Original Paper

\title{
Study on Association between Chronic Idiopathic Urticaria and Helicobacter Pylori Infection in Armed Forces Personnel
}

\author{
Hasan $\mathrm{MS}^{1}$, Khan $\mathrm{MSI}^{2}$, Nayeem $\mathrm{J}^{3}$
}

\begin{abstract}
Introduction: Chronic Idiopathic Urticaria (CIU) has an estimated prevalence of $35-65 \%$ and impacts 15 to $25 \%$ of the population at some point in their lives. Studies have shown the possible involvement of Helicobacter pylori ( $\mathrm{H}$. pylori) infection in chronic idiopathic urticaria $(\mathrm{ClU})$, but the relationship remains controversial.
\end{abstract}

Objective: To quantitatively assess the association between $\mathrm{H}$. pylori infection and chronic idiopathic urticaria.

Materials and Methods: This was a case-control type of analytical study and 100 patients were enrolled fifty patients of CIU fulfilling inclusion criteria with no identifiable cause were taken as case and patients without urticaria were taken as control, attending in the department of Dermatology \& Venereology, $\mathrm{CMH}$ Dhaka for treatment from May 2015 to Aug 2016. Helicobacter pylori infection was confirmed by serum $\lg \mathrm{G}$ for $\mathrm{H}$. pylori test.

Results: The result showed that $\mathrm{H}$. pylori infection significantly affected a high percentage of patients 30 $(60 \%)$ with chronic idiopathic urticaria. Male respondents were more positive $16(53.3 \%)$ than female $14(46.7 \%)$, in the middle aged $31-50$ year about $18(60 \%)$ and triple drug therapy was successful in $16(53.33 \%)$ patients in whom $\mathrm{H}$. pylori was detected.

Conclusion: Urticaria is a common clinical disorder with complex triggering factors. Chronic urticaria has provided evidence that enteric infection with $\mathrm{H}$. pylori may induce the disease. In this case control study, it was evident that chronic idiopathic urticaria was associated with positive serum IgG for $\mathrm{H}$. Pylori. A trial of $\mathrm{H}$. pylori eradication therapy may be offered to patients with $\mathrm{ClU}$ and evidence of $\mathrm{H}$. pylori infection.
Key-words: Chronic idiopathic urticaria, Helicobacter pylori, Armed Forces.

\section{Introduction}

Chronic idiopathic urticaria $(\mathrm{CIU})$ is defined as the occurrence of daily or almost daily, wheals and itching for at least 6 weeks, with no obvious cause. The term chronic idiopathic urticaria makes no assumption about number of patients. It is associated with various aggravating factors including drugs, food and food additives, infections and infestations (hidden or overt bacterial, viral, fungal, and protozoal agents), systemic diseases etc have been reported as possible initiating factors. But the etiology for most cases remains unknown and therapy is largely directed at symptomatic care. Up to $50 \%$ of the population show evidence of past or present $\mathrm{H}$. pylori infection and at least $30 \%$ of patients with CIU have infection with this organism ${ }^{1}$. It is definitely suspected in the etiopathogenesis of gastrointestinal disorders, such as gastritis, peptic ulcer, gastric carcinoma and lymphoma ${ }^{2}$. Recent epidemiological and experimental data have pointed to a strong relation of $\mathrm{H}$. pylori infection with the development of many extra gastric diseases, such as cardiovascular, immunologic, and some skin diseases ${ }^{3}$.

Despite numerous studies, the role of $\mathrm{H}$. pylori in chronic urticaria is still a challenge for researchers. The pathogenesis by which $\mathrm{H}$. pylori can induce or maintain urticaria are not fully understood. There are several hypotheses about the role of $\mathrm{H}$. pylori in chronic urticaria.

According to some hypotheses, an autoimmune mechanism in which molecular mimicry between $\mathrm{H}$. pylori lipopolysaccharide (LPS) and Lewis group antigen, can occur in autoimmune type-B gastritis ${ }^{4,5}$. Thus, positive autologous serum skin tests in patients with chronic urticaria, have

1. Col Md Sayeed Hasan, MBBS, DDV, FCPS, Professor and Head, Department of Demratology \& Venerology, AFMC, Dhaka

2. Col Md Shirajul Islam Khan, MBBS, DDV, MCPS, FCPS, Classified Specialist in Dermatology \& Venerology, CMH, Dhaka

3. Maj Jannatun Nayeem, MBBS, DDV, Dermatologist, $\mathrm{CMH}$, Dhaka. 
been associated with $\mathrm{H}$. pylori infection ${ }^{6}$. In some patients with chronic urticaria, but not all, autologous serum skin tests became negative after eradication of $H$. pylori infection. In some cases, specific IgE antibodies have been described for $\mathrm{H}$. pylori antigens, both in patients with chronic urticaria and in patients with complete remission after eradication of $\mathrm{H}$. pylori infection ${ }^{7}$.

In addition, it was demonstrated that $\mathrm{H}$. pylori can increase serum and tissue levels of nitrous oxide (NO), a free radical which plays an important role in various physiological processes in the skin, including vasodilatation, inflammation and immunomodulation ${ }^{8}$.

$H$. pylori induces a strong inflammatory response in the gastric mucosa and results in the expression of a wide spectrum of cytokines, chemokines and eicosanoids such as interleukin-8 (IL-8), prostaglandin E2(PGE2) and leukotriene B4(LTB4). Released from the epithelial cells, these potent pro-inflammatory mediators promote inflammation and tissue damage locally as well as induce migration and activation of neutrophils, macrophages, lymphocytes and plasma cells to the site of infection?

In $\mathrm{H}$. Pylori infected patients with chronic urticaria, significant increases in gastric eosinophil infiltration and in production of gastric juice eosinophil cationic protein production (ECP) were described and $\mathrm{H}$. pylori eradication resulted in a significant decrease in both ${ }^{10}$.

Another proposed mechanism is the increased gastric vascular permeability during $\mathrm{H}$. pylori infection, resulting in increased exposure of the host to food allergens ${ }^{11}$. In support of this hypothesis, duodenal ulcer patients have a higher incidence of allergic manifestations compared with control groups ${ }^{12}$.

On the other hand, the severity of urticarial symptoms can be related to $\mathrm{H}$. pylori density and the intensity of inflammatory infiltration observed in the gastric biopsy ${ }^{13}$.

$H$. pylori modulates also the endocrine and physiological functions of the stomach. Studies have shown that serum pepsinogen (PG)I, sPGIl and gastrin (G-17) levels are high in the presence of $\mathrm{H}$. pylori infection related to non-atrophic chronic gastritis, knowing the relationship between gastrin, mast cells and skin. In addition, it was demonstrated that their serum levels significantly decreased after eradication of $H$. pylori infection ${ }^{9}$. Thus present study is conducted to find out the correlation of chronic idiopathic urticaria with H.pylori infection.

\section{Materials and Methods}

Case-control type of analytical study and 100 patients were enrolled in this study. 50 patients of CIU fulfilling inclusion criteria with no identifiable cause were taken as case (Group-A) and patients without urticaria were taken as control (Group-B), attending in the department of Dermatology and Venereology, $\mathrm{CMH}$ Dhaka for treatment from May 2015 to Aug 2016. Purposive type of non-probability sampling method was followed in this study. Total sample Size: 50 patients and 50 controls.

The preliminary screening panel for each patient included the complete history, physical examination and laboratory tests i.e Complete blood count including differential count, total $\lg \mathrm{E}$, total eosinophil count, sedimentation rate, serum $\lg G$ for $H$. pylori, urine routine examination, liver function test, serum test for hepatitis $B$ and $C$, stool examination for parasites and ova. Inclusion criterias were (1) Clinically diagnosed case of CIU, (2) Both male and female patients; (3) Age of the patients between 15-60 years, (4) Patient who gave informed consent. Exclusion criterias were (1) Patients suffering from other than CIU, (2) Patient suffering from hematological, renal or liver disorder, (3) Patients of CIU with pregnancy, (4)Patients with urticarial vasculitis, (5) Patients who had taken proton pump inhibitors and antibiotics within the preceding 4 weeks, (5) Chronic urticaria with known etiology: physical urticaria, cholinergic urticaria, hives caused by food allergy, medications, connective tissue and thyroid diseases, malignancies, patients who were receiving corticosteroids, immunosuppressive therapy, patients with ASST (+).

Statistical analysis of the results was obtained by computer based software SPSS-20 and the data was analyzed using Chi square test and paired test in appropriate situations. $P$ value $<0.05$ was considered as minimum level of statistical significance.

\section{Results}

Table-I: Distribution of patients according to sex $(n=100)$

\begin{tabular}{|l|c|c|c|}
\hline \multirow{2}{*}{ Sex } & \multicolumn{2}{|c|}{ Group } & \multirow{2}{*}{$\begin{array}{c}\text { P } \\
\text { value }\end{array}$} \\
\cline { 2 - 3 } & Case (A) & Control (B) & \multirow{2}{*}{0.157} \\
\hline Male & $20(40 \%)$ & $30(60 \%)$ & \\
\hline Female & $30(60 \%)$ & $20(40 \%)$ & \\
\hline
\end{tabular}

${ }^{*}$ Chi-square test was done to measure the level of significance.

Table-I shows the distribution of patients according to sex. In Group-A female 30(60.0\%) is predominant than 
male $20(40.0 \%)$ at the ratio of $3: 2$. In Group-B, male $30(60 \%)$ is predominant than female $20(40 \%)$. The difference between these two groups are not statistically significant $(P=0.157)$.

Table-II: Distribution of patients according to age group $(n=100)$

\begin{tabular}{|c|c|c|c|}
\hline \multirow{2}{*}{ Age group } & \multicolumn{2}{|c|}{ Group } & \multirow{2}{*}{$\begin{array}{c}P \\
\text { value }\end{array}$} \\
\hline & Case (A) & Control (B) & \\
\hline$<=20$ & $2(4 \%)$ & $6(12 \%)$ & \multirow{7}{*}{0.053} \\
\hline $21-30$ & $10(20 \%)$ & $14(28 \%)$ & \\
\hline $31-40$ & $20(40 \%)$ & $24(48 \%)$ & \\
\hline $41-50$ & $10(20 \%)$ & $2(4 \%)$ & \\
\hline$>=50$ & $8(16 \%)$ & $4(8 \%)$ & \\
\hline Total & $50(100 \%)$ & $50(100 \%)$ & \\
\hline Mean \pm SD & $38.96 \pm 10.632$ & $33.00 \pm 10.607$ & \\
\hline
\end{tabular}

${ }^{*} t$ test was done to measure the level of significance

Table-II shows the distribution of patient according to age group. In Group-A, majority of patient, 20(40\%) cases was found in 31-40 years of age group. In Group-B, majority of patient $24(48 \%)$ cases was found in 31-40 years of age group. The Mean $\pm S D$ of Group-A and Group-B are in $38.96 \pm 10.632$ and $33.00 \pm 10.607$ years respectively. The different between Group-A and Group- $B$ is not statistically significant $(P=0.053)$.

Table-III: Distribution of patients according to occupation $(n=100)$

\begin{tabular}{|l|c|c|c|}
\hline \multirow{2}{*}{ Occupation } & \multicolumn{2}{|c|}{ Group } & \multirow{2}{*}{$\begin{array}{c}\text { P } \\
\text { value }\end{array}$} \\
\cline { 2 - 3 } & Case (A) & Control (B) & \\
\hline Military personnel & $12(24 \%)$ & $22(44 \%)$ & \\
\hline Housewife & $28(56 \%)$ & $16(32 \%)$ & \multirow{2}{*}{0.236} \\
\hline Student & $2(4 \%)$ & $6(12 \%)$ & \\
\hline Civil employee & $8(16 \%)$ & $6(12 \%)$ & \\
\hline Total & $\mathbf{5 0 ( 1 0 0 \% )}$ & $\mathbf{5 0 ( 1 0 0 \% )}$ & \\
\hline
\end{tabular}

Table-III shows the distribution of patient according to occupation. In Group-A majority are housewives $28(56 \%)$ cases followed by military personnel $12(24 \%)$ cases. In Group-B majority are military personnel $22(44 \%)$ cases followed by housewife $16(32 \%)$ cases. The difference between Group-A and Group-B are not statistically significant $(P=0.236)$.

Table-IV: Distribution of patients according to Serum IgG for H.pylori ( $\mathrm{n}=100)$

\begin{tabular}{|l|c|c|c|}
\hline \multirow{2}{*}{$\begin{array}{l}\text { Serum IgG } \\
\text { for H.pylori }\end{array}$} & \multicolumn{2}{|c|}{ Group } & \multirow{2}{*}{$\begin{array}{c}\text { Case (A) } \\
\text { value }\end{array}$} \\
\cline { 2 - 3 } Positive & $30(60 \%)$ & $16(32 \%)$ & \\
\hline Negative & $20(40 \%)$ & $34(68 \%)$ & 0.047 \\
\hline Total & $\mathbf{5 0 ( 1 0 0 \% )}$ & $\mathbf{5 0 ( 1 0 0 \% )}$ & \\
\hline
\end{tabular}

${ }^{*}$ Chi-square test was done to measure the level of significance

Table-IV shows the distribution of patients (Group-A) according to serum $\lg G$ for $H$. pylori were about $60 \%$ cases (30 respondents) positive for $\lg G$ and $20(40 \%)$ patients were negative. On the contrary, among the controls (Group-B) 32\% (16 respondents) was positive and $68 \%$ (34 respondents) were negative for lgG.

Table-V: Distribution of cases according to sex $(n=50)$

\begin{tabular}{|l|c|c|c|}
\hline \multirow{2}{*}{ Sex } & \multicolumn{2}{|c|}{ Serum IgG for H.pylori } & \multirow{2}{*}{$\begin{array}{c}\text { P } \\
\text { value }\end{array}$} \\
\cline { 2 - 3 } & Positive & Negative & \\
\hline Male & $16(53.3 \%)$ & $4(20 \%)$ & \multirow{2}{*}{0.096} \\
\hline Female & $14(46.7 \%)$ & $16(80 \%)$ & \\
\hline Total & $\mathbf{3 0 ( 1 0 0 \% )}$ & $\mathbf{2 0 ( 1 0 0 \% )}$ & \\
\hline
\end{tabular}

${ }^{*}$ Chi-square test was done to measure the level of significance

Table- $V$ shows the distribution of sex for positivity of IgG for $\mathrm{H}$. pylori, male respondents were more positive $16(53.3 \%)$ than female respondents $14(46.7 \%)$. Among the 20 negative results, 16 respondents $(80 \%)$ were female and 4 respondents $(20 \%)$ were males.

Table-VI: Distribution of Improvement after triple therapy according to sex $(n=30)$

\begin{tabular}{|l|c|c|c|}
\hline \multirow{2}{*}{ Occupation } & \multicolumn{2}{|c|}{ Serum IgG for H.pylori } & \multirow{2}{*}{$\begin{array}{c}\text { P } \\
\text { value }\end{array}$} \\
\cline { 2 - 3 } & Positive & Negative & \\
\hline Military personnel & $12(40 \%)$ & $0(0 \%)$ & \\
\hline Housewife & $12(40 \%)$ & $16(80 \%)$ & \multirow{2}{*}{0.239} \\
\hline Student & $2(6.7 \%)$ & $0(0 \%)$ & \\
\hline Civil employee & $4(13.3 \%)$ & $4(20 \%)$ & \\
\hline Total & $\mathbf{3 0 ( 1 0 0 \% )}$ & $\mathbf{2 0 ( 1 0 0 \% )}$ & \\
\hline
\end{tabular}

Table-VI shows eradication therapy was successful in 16(53.33\%) patients, $8(26.66 \%)$ patients did not respond to therapy and $6(20 \%)$ patients did not complete the study.

Table-VIl: Distribution of cases according to age group ( $n=50$ )

\begin{tabular}{|c|c|c|c|}
\hline \multirow{2}{*}{$\begin{array}{l}\text { Age } \\
\text { group }\end{array}$} & \multicolumn{2}{|c|}{ Serum IgG for H.pylori } & \multirow{2}{*}{$\begin{array}{c}P \\
\text { value }\end{array}$} \\
\hline & Positive & Negative & \\
\hline$<=20$ & $2(6.7 \%)$ & $0(0 \%)$ & \multirow{7}{*}{0.815} \\
\hline $21-30$ & $6(20 \%)$ & $4(20 \%)$ & \\
\hline $31-40$ & $10(33.3 \%)$ & $10(50 \%)$ & \\
\hline $41-50$ & $8(26.7 \%)$ & $2(10 \%)$ & \\
\hline$>=50$ & $4(13.3 \%)$ & $4(20 \%)$ & \\
\hline Total & $30(100 \%)$ & $20(100 \%)$ & \\
\hline Mean \pm SD & $38.53 \pm 10.521$ & $39.60 \pm 11.335$ & \\
\hline
\end{tabular}

${ }^{*} t$ test was done to measure the level of significance

Table-VII shows among the cases highest number of $\mathrm{H}$. pylori infection were found in middle aged 31-50 year about $18(60 \%)$ followed by young aged $21-30$ year and below about $8(26.7 \%)$.

Table-VIII: Distribution of cases according to occupation $(n=50)$

\begin{tabular}{|c|c|c|c|}
\hline \multirow[t]{2}{*}{ Occupation } & \multicolumn{2}{|c|}{ Serum IgG for H.pylori } & \multirow{2}{*}{$\begin{array}{c}P \\
\text { value }\end{array}$} \\
\hline & Positive & Negative & \\
\hline Military personnel & $12(40 \%)$ & $0(0 \%)$ & \multirow{5}{*}{0.239} \\
\hline Housewife & $12(40 \%)$ & $16(80 \%)$ & \\
\hline Student & $2(6.7 \%)$ & $0(0 \%)$ & \\
\hline Civil employee & $4(13.3 \%)$ & $4(20 \%)$ & \\
\hline Total & $30(100 \%)$ & $20(100 \%)$ & \\
\hline
\end{tabular}


Table-VIII shows the incidence of serum IgG for H.Pylori amongst different occupation of the respondents, housewives and military personnel have the highest percentage $(40 \%)$.

\section{Discussion}

In this study it was found that from Table-I, in group A (patient) female was predominant than male which was $30(60.0 \%)$ and $20(40.0 \%)$ cases respectively at the ratio of 3:2 whereas Kulthanan $\mathrm{K}$ et al 2007 describes the male and female association were $21 \%$ and $79 \%$ respectively ${ }^{14}$. In another study of Lee $\mathrm{N}$ et al CU was significantly higher in females than in males $(2,466.8$ vs $1,819.2$ per 100,000 person-years, $P<0.001)^{15}$. In Group-B male was predominant than female which was 30 $(60.0 \%)$ and $20(40.0 \%)$ cases respectively. The difference between these two group is statistically significant $(P=0.157)$.

Table-Il in this study showed that in group A less than 21 years of age group was found in only $2(4 \%)$ cases, $10(20 \%)$ cases in $21-30$ years, $20(40 \%)$ cases in 31 40 years, $10(20 \%)$ cases in $41-50$ years and $8(16 \%)$ cases in 50 years to above group. In group B less than 21 years of age group was found in $6(12 \%)$ cases, 14 $(28 \%)$ cases in $21-30$ years, $24(48 \%)$ cases in $31-40$ years, $2(4 \%)$ cases in $41-50$ years and $4(8 \%)$ cases in 50 years to above group. The Mean $\pm S D$ of group $A$ and group $B$ were in $38.96 \pm 10.632$ and $33.00 \pm 10.607$ years respectively. The different between group $A$ and group $B$ is not statistically significant $(P=0.053)$. In Mogaddam MR et at study both groups (patient and control), 58\% were male and $42 \%$ were female. The mean age in the patients group was $37.64 \pm 16.04$ years and in the control group it was $37.55 \pm 16.26$ years ${ }^{16}$.

In this study when searched the positivity for IgG levels to detect $\mathrm{H}$. pylori, it was found that, in case of serum IgG positive respondents, male respondents were greater than the female counterparts. But the result was not significant $(P=0.096)$. In group $A$ majority were housewives $28(56 \%$ ) cases followed by military personnel, civil employee and student which are $12(24 \%)$ cases, $8(16 \%)$ cases, and $2(4 \%)$ case respectively. In group B majority are military personnel $22(44 \%)$ cases followed by housewife, student and civil employee which are $16(32 \%)$ cases, $6(12 \%)$ cases and $6(12 \%)$ cases respectively (Table-III). The difference between group $A$ and group $B$ are not statistically significant $(P=0.236)$.
One of the important diagnostic tools was to see the IgG level in serum to detect $\mathrm{H}$. pylori infestation among the patients. Study showed the distribution of patients (Group-A) according to serum IgG for $\mathrm{H}$. pylori were about $60 \%$ cases (30 respondents) positive for IgG and 10 patients $(40 \%)$ were negative. On the contrary, among the controls (Group B) $32 \%$ (16 respondents) was positive and $68 \%$ (34 respondents) were negative for IgG. Chi-square test was done to measure the level of significance. The $P$ value was 0.047 . So the result was significant (Table-IV). Gaiga, P et al. 2002 found $80 \%$ CIU cases who were positive with $\mathrm{H}$. pylori infestation ${ }^{17}$.

From Table- $\mathrm{V}$ of this study it was found that distribution of sex for positivity of $\mathrm{lgG}$ for $\mathrm{H}$. pylori, male respondents were more positive 16 (53.3\%) than female respondents $14(46.7 \%)$. Among the 20 negative results, 16 respondents $(80 \%)$ were female and 4 respondents $(20 \%)$ were males. In a study of Lee $\mathrm{N}$ et al $\mathrm{H}$. pylori positivity was significantly higher in females than in males (26333 vs 18845 per 100000) among adolescent and adults older than 15 years $^{15}$.

Thirty patients with positive $\mathrm{H}$. pylori antibodies received triple therapy. Patients were evaluated for the relief of symptoms. Eradication therapy was successful in $16(53.33 \%)$ patients, $8(26.66 \%)$ patients did not respond to therapy and $6(20 \%)$ patients did not complete the study (Table-VI). This finding suggests that anti $\mathrm{H}$. pylori triple drug therapy is significantly effective in the treatment of CIU. Mogaddam MR et al found response to eradication of $\mathrm{H}$. pylori was evident in $91.67 \%$ patients in whom $\mathrm{H}$. pylori was eradicated while $8.33 \%$ patients showed no response ${ }^{16}$. A study of Qazi $\mathrm{N}$ et al also have shown there is a possible role of $\mathrm{H}$. pylori infection in the pathogenesis of CIU which is consistent with this study ${ }^{18}$.

Table-VII of this study delineated that among the cases highest number of $\mathrm{H}$. pylori infection were found in middle aged $31-50$ year about $18(60 \%)$ followed by young aged 21-30 year and below about 8 (26.7\%). Bonamigo RR et al had a research that showed young aged (20-30 years) females had higher affection of $\mathrm{H}$. pylori $(43.4 \%)^{19}$.

The incidence of serum IgG for $\mathrm{H}$. pylori amongst different occupation of the respondents, it was seen that the housewives and military personnel have the highest percentage $(40 \%)$ of positive serum IgG (Table-VIII). In Tachihara $\mathrm{R}$ et al it was the housewives who had incidence of $20 \%$ only ${ }^{20}$. 


\section{Conclusion}

Urticaria is a common clinical disorder with complex triggering factors. Chronic urticaria has provided evidence that enteric infection with $H$. pylori may induce the disease. In this small case control study, it was evident that chronic idiopathic urticaria is associated with positive serum $\lg G$ for $\mathrm{H}$. Pylori. Response to eradication therapy was evident in whom $H$. pylori infection was eradicated while few patients showed no response despite eradication of $\mathrm{H}$. pylori. It is suggested that $\mathrm{H}$. pylori infection should be included in the diagnostic work up of patients with no response to habitual treatment for CIU. This study support further investigation into the involvement of $\mathrm{H}$. pylori infection in CIU and offer the possibility of an effective treatment without adverse effect for such a chronic, symptomatic, quality-of-life-affecting disease.

\section{References}

1. Tüzün $Y$, Keskin $S$, Kote E. The role of Helicobacter pylori infection in skin diseases: Facts and controversies. Clin Dermatol 2010; 28(5):478-82.

2. Suerbaum S, Michetti P. Helicobacter pylori infection. N Engl J Med 2002; 347(15):1175-86.

3. Goodman KJ, Joyce SL, Ismond KP. Extragastric diseases associated with Helicobacter pylori infection. Curr Gastroenterol Rep 2006; 8(6):458-64.

4. Appelmelk BJ, Simoons-Smit I, Negrini R et al. Potential role of molecular mimicry between Helicobacter pylori lipopolysaccharide and host Lewis blood group antigens in autoimmunity. Infect Immun 1996; 64(6):2031-40.

5. Negrini R, Savio A, Poiesi C et al. Antigenic mimicry between Helicobacter pylori and gastric mucosa in the pathogenesis of body atrophic gastritis. Gastroenterology 1996; 111(3):655-65.

6. Hizal $M$, Tüzün $B$, Wolf $R$, Tüzün $Y$. The relationship between Helicobacter pylori IgG antibody and autologous serum test in chronic urticaria. Int J Dermato/ 2000; 39(6):443-5.

7. Shiotani A, Okada K, Yanaoka K et al. Beneficial effect of Helicobacter pylori eradication in dermatologic diseases. Helicobacter 2001; 6(1):60-5.
8. Gürer MA, Erel A, Erbaş D et al. The seroprevalence of Helicobacter pylori and nitric oxide in acne rosacea. Int $J$ Dermatol 2002; 41(11):768-70.

9. Myllyluoma E. The role of probiotics in Helicobacter pylori infection. Helsinki 2007:20-1.

10. Ojetti V, Armuzzi A, De Luca A et al. Helicobacter pylori infection affects eosinophilic cationic protein in the gastric juice of patients with idiopathic chronic urticaria. Int Arch Allergy Immunol 2001; 125(1):66-72.

11. Buhner S, Reese I, Kuehl F et al. Pseudoallergic reactions in chronic urticaria are associated with altered gastroduodenal permeability. Allergy 2004; 59(10):1118-23.

12. Hernando-Harder AC, Booken N, Goerdt S et al. Helicobacter pylori infection and dermatologic diseases. Eur $J$ Dermatol 2009; 19(5):431-44.

13. Abdou AG, Elshayeb El, Farag AG et al. Helicobacter pylori infection in patients with chronic urticaria: Correlation with pathologic findings in gastric biopsies. Int J Dermatol 2009; 48(5):464-9.

14. Kulthanan $\mathrm{K}$, Jiamton S, Thumpimukvatana $\mathrm{N}$ et al. Chronic idiopathic urticaria: Prevalence and clinical course. J Dermatol 2007; 34(5):294-301.

15. Lee N, Jeong-Dong Lee, Hyun-Young Lee et al. Epidemiology of Chronic Urticaria in Korea Using the Korean Health Insurance Database, 2010-2014. Allergy Asthma Immunol Res 2017; 9(5): $438-45$.

16. Mogaddam MR, Yazdanbod A, Ardabili NS et al. Relationship between Helicobacter pylori and idiopathic chronic urticaria: Effectiveness of Helicobacter pylori eradication. Postepy Dermatol Alergol 2015; 32(1):15-20

17. Gaig P, García-Ortega P, Enrique E et al. Efficacy of the eradication of Helicobacter pylori infection in patients with chronic urticaria. A placebo-controlled double blind study. Allergol Immunopathol (Madr) 2002; 30(5):255-8.

18. Qazi, N, Samadani AJ, Jamali S et al. Chronic Idiopathic Urticaria and Helicobacter Pylori Infection: Effect of Eradication Therapy on the Relief of Symptoms. JLUMHS 2013; 12(03):172-6.

19. Bonamigo RR, Leite CS, Bakos L. Association of helicibacter pylori and chronic idiopathic urticaria. Rev Assoc Med Bras (1992) 1999; 45(1):9-14.

20. Tachihara R, Kawana S, Matsuhisa $T$ et al. Helicobacter pylori as an underlying pathogen of chronic urticaria Source. Journal of Dermatological Science 1998; 16:114-114(1). 